\section{CONCEITOS, CAUSAS E REPERCUSSÕES DA VIOLÊNCIA SEXUAL CONTRA A MULHER NA ÓTICA DE PROFISSIONAIS DE SAÚDE}

\author{
Concepts, causes and repercussions of sexual violence against \\ women from the perspective of healthcare professionals
}

Conceptos, causas y repercusiones de la violencia sexual contra la mujer a partir de la opinión de profesionales sanitarios

\section{RESUMO}

Objetivo: Analisar os sentidos atribuídos por profissionais de saúde aos conceitos, causas e repercussões da violência sexual contra a mulher. Método: Estudo qualitativo realizado com 68 profissionais de saúde de nível superior integrantes de equipe multiprofissional de nove hospitais públicos do município de Fortaleza/CE, entre agosto e dezembro de 2013, por meio de entrevista semiestruturada, a qual norteou a coleta de dados, sendo estes submetidos à análise temática dos núcleos de sentido que emergiram. Resultados: Entre os sentidos atribuídos ao conceito de violência sexual, destacam-se a violação dos direitos humanos e ênfase na perpetuação das questões de gênero; quanto às causas, sobressaiu o machismo, a existência de patologias do agressor e a reprodução da violência familiar as repercussões atingem aspectos psicológicos, além da exposição a doenças e agressões físicas. Conclusão: O estudo possibilitou a análise dos sentidos atribuídos à violência sexual pela ótica dos profissionais de saúde investigados, que divergiram sobre a desigualdade de gênero e contexto social, cujas causas foram apontadas como sendo a cultura machista, a falta de informação das mulheres sobre os seus direitos e as questões sociais. Observou-se a dificuldade dos profissionais em trabalhar com o tema.

Descritores: Violência Sexual; Serviços de Saúde da Mulher; Assistência Integral à Saúde.

\section{ABSTRACT}

Objective: To analyze the meanings given by health professionals to the concepts, causes and repercussions of sexual violence against women. Methods: Qualitative study conducted with 68 higher degree health professionals of the multiprofessional team of nine public hospitals in the municipality of Fortaleza, Ceará, between August and December 2013 using semi-structured interviews to collect data that underwent thematic analyses of the themes that emerged. Results: The main meanings given to the concept of sexual violence were the violation of human rights and the emphasis on the perpetuation of gender issues; the main causes were misogyny, the existence of pathologies in the aggressors, the reproduction of family violence - the repercussions affect psychological aspects and lead to the exposure to disease and physical assaults. Conclusion: The study enabled the analysis of the meanings given to sexual violence from the perspective of the professionals interviewed, who presented different views regarding gender inequality and social context. The causes highlighted were misogyny, women's lack of information on their rights and social issues. It was observed that professionals had difficulties addressing the issue.

Descriptors: Sexual Violence; Women's Health Services; Comprehensive Health Care.
Artigo Original

Juliana da Fonseca Bezerra ${ }^{(1)}$

Raimunda Magalhães da Silva ${ }^{(2)}$

Ludmila Fontenele Cavalcanti ${ }^{(3)}$

Juliana Luporini do

Nascimento $^{(1)}$

Luiza Jane Eyre de Souza

Vieira $^{(2)}$

Gracyelle Alves Remigio

Moreira $^{(4)}$

1) Universidade Estadual de Campinas -

UNICAMP - Campinas (SP) - Brasil

2) Universidade de Fortaleza - UNIFOR Fortaleza - (CE) - Brasil

3) Universidade Federal do Rio de Janeiro UFRJ - Rio de Janeiro - (RJ) - Brasil

4) Associação Ampla UECE/UFC/UNIFOR - Fortaleza - (CE) - Brasil

Recebido em: 05/01/2016

Revisado em: 20/02/2016

Aceito em: 23/03/2016 


\section{RESUMEN}

Objetivo: Analizar los sentidos atribuidos por los profesionales sanitarios a los conceptos, causas y repercusiones de la violencia sexual contra la mujer. Métodos: Estudio cualitativo realizado con 68 profesionales sanitarios con educación superior participantes del equipo multiprofesional de nueve hospitales públicos del municipio de Fortaleza/CE entre agosto y diciembre de 2013 a través de entrevista semiestructurada la cual orientó la recogida de datos los cuales fueron sometidos al análisis temático de los núcleos de sentido. Resultados: Entre los sentidos atribuidos al concepto de violencia sexual, se destacan la violación de los derechos humanos y el énfasis de la perpetuación de las cuestiones de género; entre las causas se destacó el machismo, las patologías del agresor y la reproducción de la violencia familiarlas repercusiones alcanzan los aspectos psicológicos además de la exposición para enfermedades y agresiones físicas. Conclusión. El estudio ha permitido el análisis de los sentidos atribuidos a la violencia sexual a partir de la opinión de profesionales sanitarios investigados que divergieron sobre la desigualdad de género y el contexto social cuyas causas fueron apuntadas como la cultura machista, la falta de información de las mujeres sobre sus derechos y las cuestiones sociales. Se observó la dificultad de los profesionales para trabajar con el tema.

Descriptores: Violencia Sexual; Servicios de Salud para Mujeres; Atención Integral de Salud.

\section{INTRODUÇÃO}

A Violência Sexual (VS) transcende fronteiras territoriais, educacionais, socioculturais e geracionais, configurando-se como um problema de magnitude mundial, mesmo com os contornos específicos para contextos diferenciados. Mostra-se como uma das expressões da violência de gênero e firma-se como violação dos direitos humanos, sendo tema de preocupação mundial em virtude dos danos causados à saúde individual e coletiva, alto impacto na morbimortalidade de mulheres e repercussões na economia dos países ${ }^{(1)}$.

A literatura reitera que a desigualdade de gênero é um dos fatores que perpetua as heterogeneidades sociais, fundamentadas na diferença entre os sexos. Essa cristalização que circunda o senso comum subjuga as mulheres e favorece imposições estigmatizantes, prevalecentes nos contextos social, econômico, cultural e político, ganhando visibilidade nas constantes diferenças salariais, atribuições de cargos, funções e papeis ${ }^{(1-5)}$.

A reificação que subjaz as questões de gênero fortalece as apreensões sociais sobre a submissão feminina, além das sobreposições de violências, inclusive as sexuais, cujos principais agressores são representados pelos pais, padrastos, amigos e companheiros das mulheres ${ }^{(1-5)}$.
Relatórios apontam que uma em cada três mulheres sofreu violência física e/ou sexual em algum momento de sua vida $^{(1)}$. No Brasil, em 2013, registraram-se 50.320 estupros, correspondendo a um caso por minuto. As estatísticas não revelam o quantitativo real, estimando-se que apenas $10 \%$ das situações chegam aos serviços de saúde e de segurança pública ${ }^{(6)}$.

Apesar de se dispor de literatura ${ }^{(1-7)}$ sobre o tema, relatórios mundiais divulgando a magnitude do fenômeno, políticas, legislação, estratégias e movimentos sociais centrados em desconstruir o mover crescente das espirais da violência contra a mulher (incluindo-se a violência sexual), perduram na sociedade concepções teóricas distorcidas, fragmentadas, que reiteram as questões de gênero e reforçam o hiato das desigualdades entre homens e mulheres ${ }^{(3,7)}$.

À medida que as tentativas para romper com a violência avançam, a exemplo da promulgação dos Planos Nacionais de Política para as Mulheres e da Norma Técnica ${ }^{(7)}$. dialogando com os movimentos sociais feministas ${ }^{(8)}$, não se percebem avanços, nas mesmas proporções, da qualificação técnica e instrumental para efetivá-los ${ }^{(1,5)}$. Ancorando a complexidade para efetivar as estratégias de enfrentamento à VS contra a mulher, ponderam-se os diversos cenários políticos, administrativos, econômicos e culturais que configuram a organização geopolítica brasileira ${ }^{(1-8)}$.

A pesquisa de violência contra as mulheres realizada na OMS reafirma que as mulheres vítimas de violência têm com o pessoal de saúde o primeiro contato após sua ocorrência e, por isso, esse pessoal precisa de uma formação adequada ${ }^{(1)}$. Tomando essa construção argumentativa, aproximar-se de singularidades regionais, identificando similitudes e divergências nos construtos teóricos que possam balizar as práticas profissionais, mostra-se como um importante passo na reorientação de serviços e oferta da atenção à saúde de mulheres expostas às violências sexuais.

Ante os argumentos expostos, apreende-se a importância deste estudo, que propôs analisar os sentidos atribuídos por profissionais de saúde aos conceitos, causas e repercussões da violência sexual contra a mulher.

\section{MÉTODOS}

Trata-se de um estudo de abordagem qualitativa, realizado em nove serviços de saúde, oito de nível secundário e um terciário, da rede municipal de saúde de Fortaleza/CE, no período de agosto a dezembro de 2013. Entre esses serviços, cinco hospitais prestavam atendimento em ginecologia, obstetrícia e pediatria, três eram referência para os casos menos graves na área de traumato-ortopedia e um em procedimentos de alta complexidade. A escolha da instância municipal justifica-se tanto pelo maior número de serviços voltados para a atenção a essa demanda quanto pelo protagonismo na articulação da rede de serviços locais. 
Participaram das entrevistas 68 profissionais de saúde de nível superior integrantes de equipe multiprofissional, envolvidos na atenção às mulheres em situação de VS nos referidos serviços. Não se utilizou saturação da amostra, pois o interesse do estudo era obter uma amostra baseada na diversidade da atenção no município de Fortaleza/CE.

Os critérios de inclusão foram: profissionais que trabalhavam no serviço municipal de saúde, nos serviços especializados em saúde da mulher, com maior tempo de serviço e em diferentes categorias profissionais. Excluíramse do estudo os profissionais com menos de seis meses de atuação no serviço e os que se recusaram a participar do estudo.

Houve a participação média aproximada de sete profissionais da saúde por instituição, distribuídos nas seguintes categorias profissionais: enfermeiros(as) (19), assistentes sociais (19), médicos(as) (17), psicólogos(as) (12) e pedagoga (01).

Para a produção dos dados, utilizou-se a entrevista semiestruturada $^{(9)}$, com questões relativas à identificação e formação profissional, inserção institucional, qualificação para a atenção às mulheres em situação de violência sexual e os sentidos atribuídos a VS contra a mulher.

A identificação dos profissionais para as entrevistas deu-se por indicação, enfatizando o tempo de serviço e a aceitação destes em participarem do estudo. Utilizaramse os critérios de inclusão e a produção de uma agenda de entrevistas, com dia e horário favoráveis para cada participante. Realizou-se a coleta de dados nos serviços de saúde analisados, em sala reservada. As entrevistas foram gravadas com consentimento dos informantes. O tempo total das entrevistas é estimado em 28 horas e meia de gravação, com tempo médio aproximado de 25 minutos por entrevista.

Após a transcrição, realizou-se uma leitura flutuante de cada entrevista e procedeu-se com a organização do material empírico. Em seguida, empreendeu-se a análise de conteúdo na modalidade temática, guiando-se pela trajetória de análise ${ }^{(9)}$. Realizou-se uma leitura detalhada do material e identificaram-se núcleos de sentido; posteriormente, reagruparam-se buscando temáticas mais abrangentes e melhor delimitadas sobre os sentidos atribuídos à violência sexual pelos profissionais de saúde, identificação das causas da violência sexual e as repercussões da violência sexual para a mulher.

Para a representação das falas dos entrevistados, utilizou-se a letra inicial da categoria profissional seguida do número da entrevista.

A pesquisa obteve aprovação do Comitê de Ética em Pesquisa da Secretaria Municipal de Saúde e Defesa Civil do Rio de Janeiro, com parecer 45A/2013. Este estudo faz parte de um estudo multicêntrico com o Núcleo de Políticas Públicas, Indicadores e Identidades (NUPPII) da Universidade Federal do Rio de Janeiro (UFRJ), intitulado “Análise dos serviços de saúde na atenção às mulheres em situação de violência sexual: estudo comparativo em duas capitais brasileiras".

\section{RESULTADOS E DISCUSSÃO}

\section{Caracterização dos participantes}

Dos 68 participantes, 32 estavam na faixa etária de 45 a 54 anos. Sobre a situação conjugal, 37 dos entrevistados consideravam-se unidos. A religião católica obteve maior representatividade $(n=45)$, seguida da espírita e da evangélica. A questão religiosa interfere diretamente nos sentidos atribuídos sobre a VS, principalmente quando existe a necessidade de realizar o aborto legal ${ }^{(10)}$. Encontraram-se obstáculos significativos na atuação de grupos religiosos que insistem em reconhecer somente deveres reprodutivos e em manter suas concepções dogmáticas de forma hegemônica para toda a sociedade ${ }^{(10)}$.

A maioria (20 entrevistados) dos profissionais estava com 10 a 20 anos de formados, 19 realizaram especialização, 10 tinham mestrado e doutorado. A pós-graduação, para o profissional de saúde, independentemente da sua formação, é importante para habilitá-lo e capacitá-lo para realizar determinada função e sensibilizá-lo para a importância da pesquisa $^{(11,12)}$. Sabe-se que a realização das funções torna-se mais segura e consciente pelos profissionais quando estes buscam constantemente capacitações nos cursos e pósgraduações $^{(11,12)}$.

Sobre o tempo de serviço, 22 profissionais tinham de 11 a 20 anos de trabalho nas unidades, o que representa uma experiência consolidada sobre as ações de saúde desenvolvidas nos serviços. Segundo estudo ${ }^{(13)}$ realizado na região Sul com residentes de saúde da família e supervisores com formação multidisciplinar, identificou-se que, com o avançar da idade, os profissionais ficam mais experientes e empoderam-se de conhecimentos para atender as mulheres nos serviços de saúde ${ }^{(13)}$.

\section{Os sentidos atribuídos à violência sexual pelos profissionais de saúde}

Para o contexto do presente artigo, os sentidos atribuídos podem ser compreendidos como a definição da VS pelos profissionais de saúde. Os sentidos estão associados com a violação dos direitos, segurança pública e violência de gênero.

A violação dos direitos humanos das mulheres é identificada pelos atos físicos, psicológicos e mentais. O profissional Mo29 definiu: 
"Violência sexual é definida com um ato em que você tem uma agressão física e também psicológica, e às vezes com dano moral, muitas vezes irreversível."

A VS não é restrita aos casos que acontecem com desconhecidos, pois a fração mais representativa dos casos está relacionada com a VS crônica, aquela que ocorre nos domicílios e passa despercebida pela sociedade, havendo uma constante violação dos direitos das mulheres ${ }^{(5-7)}$.

A temática é discutida desde 1979 na Convenção sobre a Eliminação de todas as Formas de Discriminação contra a Mulher (Cedaw) $)^{(14-16)}$, que compreende a ação como "toda a distinção, exclusão ou restrição baseada no sexo e que tenha por objeto ou resultado prejudicar ou anular o reconhecimento, gozo ou exercício pela mulher, independentemente de seu estado civil, sobre a base na igualdade do homem e da mulher, dos direitos humanos e das liberdades fundamentais das esferas política, econômica, social, cultural e civil ou em qualquer outra esfera"(15).

Os achados da atual pesquisa corroboram com o de outro estudo $^{(17)}$, que identifica a violência sexual como uma violação dos direitos e associada às relações conjugais, em que o agressor e a mulher possuem uma união consensual estabelecida e a mulher, por sentir-se obrigada, pelo casamento, mantém relações sexuais com o parceiro mesmo sem desejar.

"Ela começou a ser obrigada a fazer o que ela não queria. O marido chegava do trabalho, chegava embriagado, chegava de madrugada, a hora que fosse, e ele queria forçar que ela tivesse uma relação sexual. Chegou a um ponto de um dia ela apanhar dele e ser forçada a fazer, $e$ foi o dia que ela resolveu vir pra cá." (Ea42)

Os profissionais investigados na presente pesquisa identificaram a VS como um caso de polícia, responsabilizando o serviço de segurança pública pela conduta do agressor. Com isso, retiram da área da saúde a responsabilidade da atenção com a mulher, segundo a fala de Pa53:

"Eu acho um caso de polícia, né? Uma coisa séria. E deve ter uma preocupação maior de todas as pessoas que trabalham nessa, não só nessa área da saúde, mas também na parte juridica."

O Ministério da Saúde (MS) oferece instrumentos e ferramentas para orientar os profissionais sobre as condutas na temática de VS. Os serviços de saúde devem constituir uma rede estruturada e efetiva, composta de serviços intra e intersetorias que ofereçam à mulher uma atenção em saúde que respeite os direitos sexuais e reprodutivos, orientações sobre como sair da situação de violência sem qualquer discriminação e profissionais capacitados que assegurem a efetivação de cada etapa do atendimento ${ }^{(18,19)}$.

$\mathrm{Na}$ rede de atenção intersetorial à saúde, a segurança pública é contemplada, mas não é a única responsável pela situação da violência, pois, diante dos relatos dos profissionais estudados na atual pesquisa, identificou-se que as mulheres utilizam esse serviço como ferramenta para o atendimento integral, para denunciar o agressor e para utilizar os serviços de proteção. Uma parte dos entrevistados atribui o sentido da VS como uma maneira de prejudicar o agressor e realiza uma simulação de VS. O julgamento que os profissionais realizam com as mulheres em situação de VS também é identificado em outro estudo ${ }^{(20)}$; isso torna o atendimento discriminatório, principalmente quando existe a necessidade de realizar o aborto legal ${ }^{(20)}$.

"Eu vejo onde eu trabalho, na perícia, mulheres que simulam uma agressão, simulam um estupro, vão à delegacia, denunciam o parceiro, o companheiro, o amante, o que for, na intenção de prejudicar, porque ela sabe que hoje tem a Lei Maria da Penha e é uma lei muito rigorosa." (Mo39)

Entende-se que os profissionais questionam a denúncia da mulher e interpretam que as mulheres estão utilizando os seus direitos previstos em lei para prejudicar o provável agressor, pois a violência de gênero merece um tratamento diferenciado, tendo em vista a necessidade de superação do conflito, afinal, são relações de poder entre desiguais. Para os profissionais entrevistados, na presente pesquisa, a violência é definida como uma questão de gênero, conforme a fala representativa de $A S a 10$ :

"Essa violência, muitas vezes, ela é causada por esta mulher ser submissa, [...] ser vulnerável, então são vários os fatores que podem ocasionar essa violência, [como] o desrespeito realmente enquanto mulher."

A violência de gênero é definida como "qualquer ato que resulte dano físico ou emocional, numa relação pautada em desigualdade e assimetria entre os gêneros"(18). A questão de gênero percorre as questões culturais de ambos os envolvidos e a capacidade de enfrentamento dessa violência de gênero ${ }^{(18)}$.

Infere-se que a VS, para os profissionais analisados, é associada à expressão dos fatores sociais e culturais do homem, mas encontrou-se que nem sempre esses profissionais se responsabilizam pela conduta da atenção e conhecem as redes intra e intersetoriais de encaminhamentos da mulher. Um dos entrevistados (Mo39) assumiu a postura de duvidar da veracidade da violência sexual, pois, em alguns casos, a denúncia vem sendo utilizada pelas mulheres como ferramenta para prejudicar 
o homem. A postura desse profissional de desacreditar na mulher evolui para um atendimento esvaziado e dificulta a continuidade do tratamento, pois as mulheres sofrem uma segunda violência nesses atendimentos, quando deveriam ser acolhidas e encontrar o caminho para proteção, com o uso dos seus direitos.

Os profissionais do presente estudo também analisaram que os sentidos atribuídos dessa VS reduzem-se à privação dos direitos humanos, porém, essas violências de gênero são permeadas pelas agressões que transcendem a esfera física e sexual, comprometendo o psicológico da mulher e o seu comportamento social. Ressalta-se que essa violência aprisiona a mulher sexualmente e imprime efeitos que persistem ao longo da vida $a^{(12,15-18)}$.

\section{Identificação das causas da violência sexual}

A VS é construída em sociedade e nas relações sociais $^{(5,8,10,11,20)}$, sendo potencializada quando existe algum grau de parentesco no sentido social do ato sexual, que surge por uma relação de dominação, na medida em que as práticas e as representações dos dois sexos são assimétricas $^{(20)}$. A relação amorosa é pensada pelos homens com a lógica da conquista, sendo o ato sexual concebido como uma forma de apropriação e de posse ${ }^{(20)}$.

Diante dessa compreensão, as subtemáticas emergidas das falas dos entrevistados identificam que as causas da violência sexual correspondem à cultura machista, questões sociais, insuficiência do cumprimento e da divulgação dos aparatos legais, reprodução da violência vivenciada na família, patologia do agressor, banalização e estímulo da mídia.

A cultura machista está presente no Brasil, independentemente da região, devido ao desempenho desigual dos papéis de gênero diante da sociedade ${ }^{(20,21)}$. No contexto da saúde, as mulheres que se tornaram submissas aos homens têm entraves para relatar aos profissionais de saúde as agressões sofridas $^{(20,21)}$. O silêncio causa dor e sofrimento, e facilita a permanência do ciclo da violência, pois, com a falta de punição e a normalização da agressão, quando os envolvidos possuem uma relação socialmente estabelecida, o agressor sente-se seguro, protegido pelo status do relacionamento, para violentá-la novamente ${ }^{(21-23)}$.

No Nordeste, alguns profissionais do presente estudo identificaram o machismo como uma questão associada à cultura, segundo a fala de Po14:

“A questão cultural [d]o machismo está muito carregada no nosso... [Para o] nordestino, principalmente, a mulher tem que obedecer. Muitas vezes, [é] a condição econômica que cria aquela dependência."

A cultura é apontada como instrumento de dominação dos homens em relação às mulheres nos relacionamentos, tornando-se uma amarra para elas, pois não visualizam a legitimidade social para se desvincularem das situações de vulnerabilidade - assim ocorre a reprodução da violência ${ }^{(20,21)}$.

O agressor consegue manter as mulheres em situação de vulnerabilidade através das limitações impostas pelo poder ele que exerce sobre elas. Compreende-se que as limitações impostas às mulheres ocorrem pelos dispositivos discursivos de poder dos agressores, os quais existem apenas no aspecto do discurso, mas esse poder consegue se efetivar na prática em forma de agressões ${ }^{(18,24,25)}$.

Esse poder é culturalmente inserido em todas as classes sociais, porém, a denúncia da VS é maior na população de classes menos favorecidas economicamente ${ }^{(20,24)}$. Especulase que a possível relação entre a VS e o serviço de segurança pública acarreta na exposição e na repercussão social negativa das mulheres. Independentemente do nível social, é desconfortante a associação da VS à imagem da mulher; esse contexto dificulta a exposição da agressão aos serviços de saúde e de segurança.

"Eu acredito que ainda tenha muito disso, não apenas na classe menos favorecida, não. Eu acho que em todas as classes sociais: na classe média, na classe média alta, na elite. Eu acho que existe em todas, mas qual a diferença? Que a elite esconde muito bem, a classe media menos, e a classe considerada classe $C$ fala, mas não chegam a denunciar, e se denunciar depois retiram as queixas." (Ea6)

Para compreender o impacto das estruturas sociais e das interações nos espaços micro e macro das dimensões humanas, é necessário conhecer o impacto da modernidade nas dimensões sociais e da condição humana ${ }^{(26)}$. Os profissionais entrevistados no atual estudo elucidaram que as mulheres são, muitas vezes, dependentes financeira e psicologicamente do agressor,.Por isso, sofrem com para se desvincularem do agressor, mas a VS não é restrita a nenhuma classe social, raça ou etnia.

"A gente percebe, no atendimento, que quando as pessoas
têm menos formação [...],têm menos acesso à educação,
elas acabam sendo mais pré-disponíveis à violência
sexual.” (ASa33)

O risco de ser alvo de uma VS existe para todas as mulheres, mas as que possuem condições socioeconômicas mais desfavorecidas são propensas a permanecerem em situações de violência crônica ${ }^{(20,27-29)}$. Essa visão confronta a de outro estudo ${ }^{(30)}$, pois associa a VS como um problema voltado para a esfera social e econômica, devido ao acesso precário à educação e o desemprego ser generalizado.

"Tem muitas causas: analfabetismo, pobreza, falta de instrução, problemas financeiros e familiares. Você vê que 
a maioria dos estupros é [cometido por] alguém próximo da vítima, e a vítima tem alguma vulnerabilidade, algum fator facilitador. Então você pode contar mil coisas: migração das pessoas para os grandes centros, a pobreza e a marginalização. Tem mil, mil coisas, né? É até dificil de responder." (Mo39)

Os profissionais relacionam a VS a problemas econômicos, ao acesso à educação, ao mercado de trabalho e principalmente ao uso de álcool e drogas, sendo associada, ainda, aos locais com menor crescimento industrial e menor empoderamento das mulheres ${ }^{(31)}$.

"Os violentadores geralmente eles têm esse perfil; eles são alcoolistas, são usuários de alguma droga e as mulheres violentadas são mulheres submissas, mulheres que não têm nenhuma perspectiva, nenhum projeto de vida, e que às vezes dizem estar e aguentarem por conta de não terem para onde ir e não saberem como quebrarem essas amarras." (ASa10)

Os profissionais do presente estudo fazem uma relação do uso de álcool e droga pelo parceiro que pratica a VS. Associou-se que o álcool e as drogas são usados em situações de comemoração e de infelicidade, sendo interpretado como um mecanismo de ressarcimento para perdas e sofrimentos ${ }^{(31)}$. A causa da violência pela ótica dos profissionais ocorre pelo uso dessas substâncias fazer uma interlocução entre os fatores sociais, culturais, valores e atitudes da comunidade. Estudar a relação das substâncias psicoativas com a violência aborda um contexto macro do ser humano, pois pode aumentar a irritabilidade, reduzir o autocontrole e a capacidade cognitiva ${ }^{(31)}$.

A violência sexual não pode ser reduzida ao uso de substâncias químicas, pois está relacionada à superioridade masculina socialmente imposta e aceita por séculos, pela necessidade de controle e manutenção da mulher em uma situação de submissão, independentemente do uso ou não das drogas lícitas ou ilícitas ${ }^{(18,20,31)}$.

A patologia do agressor é outra explicação frequente entre os profissionais investigados no presente estudo, à qual recorrem para justificar a VS:

"Pelo simples fato de ser crime mesmo, [há] um distúrbio de conduta por parte do agressor. Não vejo outra razão para isso não. ”. (Mo59)

A violência como forma de exercer poder pode advir de uma necessidade de dominação do ser humano, sendo homem ou mulher, que configura o aspecto patológico, sendo por isso um distúrbio de conduta ${ }^{(4)}$.

A perpetuação da violência é um dos maiores problemas da $\mathrm{VS}^{(18)}$, pois ela passa a ser compreendida como algo natural e presente no cotidiano das mulheres, dentro da história de violência na família e nos relacionamentos. Asa17 fala sobre a transferência do machismo para aos filhos:

"A própria mulher transfere. Inconscientemente ela transfere esse machismo pros filhos e a gente vai perpetuando. [...] Assim, o rompimento desse ciclo é mais complexo durante o atendimento."

Os profissionais entrevistados na presente pesquisa sentem-se impossibilitados de romper com esse ciclo, pois acreditam que o trabalho realizado em consultas é insuficiente para competir com os estímulos da VS da cultura e da mídia, que tratam a mulher como objeto, e isso é naturalmente aceito e reproduzido na sociedade, consciente ou inconscientemente.

Esse achado corrobora com outra pesquisa ${ }^{(23)}$ que trata do importante papel da mídia (televisão e internet) e sua expressiva disseminação de mensagens que estimulam atitudes agressivas em jogos, filmes e outras atividades.

A questão de gênero contribui para o agressor exercer a dominação, pois existem desigualdades sociais e econômicas entre os sexos e a discriminação histórica contra as mulheres ${ }^{(4)}$. Esse fato torna-se um facilitador para novas violências, pois o comportamento esperado dessas mulheres, pelos parceiros, é de manter-se na condição de subordinação ${ }^{(4)}$.

$\mathrm{O}$ presente estudo encontrou que as causas da VS para os profissionais estão relacionadas à questão cultural e intimamente ligadas ao machismo, à falta de acesso à educação, à patologização, à reprodução da VS, ao uso de álcool e drogas e ao estímulo da mídia. Identificou-se a necessidade de uma capacitação que possibilite a reflexão do profissional para desconstruir a naturalização de gênero, representada nas falas que de certa forma recorrem a outros elementos, como o uso de álcool e drogas, para justificar a VS.

Os fatores pontuados pelos profissionais analisados no estudo em questão são, pela ótica deles, as causas da VS, que desenvolvem questões para serem avaliadas e discutidas em busca de encontrar estratégias para a reformulação de ações e políticas públicas, devido à identificação in loco do problema, a fim de alcançar a demanda identificada pelos profissionais.

\section{As repercussões da violência sexual para a mulher}

Os aspectos pontuados pelos profissionais analisados na atual pesquisa, nesta temática, foram: a agressão, que se reflete nas esferas psicológica e física; a busca pelos direitos sexuais e reprodutivos; e a continuação do ciclo da violência.

Para os profissionais da saúde estudados, a VS está intimamente relacionada às lesões físicas da mulher, desde 
uma lesão superficial até o óbito. Os traumas físicos são relatados na fala de $\mathrm{Ma} 23$ :

"A gente pode ter violência sexual, por exemplo, que pode levar a uma lesão de vagina, com reto, com bexiga, com repercussões físicas mesmo para aquela paciente."

O serviço especializado em saúde da mulher deve oferecer recursos para o atendimento integral e para a reabilitação da integridade física das pacientes, pois as consequências para o sistema reprodutivo são amplas, variando desde a exposição da Doença Sexualmente Transmissível (DST) até a gestação indesejada ${ }^{(17)}$, podendo alcançar a incapacidade de engravidar. Os profissionais investigados relatam o risco a que essas mulheres estão expostas, conforme é relatado a seguir:

"Às vezes, repercussões do ponto de vista reprodutivo, [como] ter que se submeter a uma cirurgia com retirada de órgãos reprodutivos e não poder mais engravidar. Tem a questão da transmissão de Doenças Sexualmente Transmissiveis, que podem acontecer num momento desse também, da violência sexual. A gravidez, que pode vir disso também, como uma outra consequência." (Ma23)

Os pacientes buscam o serviço de saúde no episódio de emergência para examinar e medicalizar o corpo como um evento pontual, mas, quando se trata da VS, esse comportamento pode ser um agente causador para a recidiva, pois os danos relacionados à saúde mental são mais profundos às mulheres ${ }^{(12,13,18,24)}$. Quando os profissionais conhecem os procedimentos e encaminhamentos previstos na Norma Técnica ${ }^{(7)}$, esses riscos são minimizados, mas o atendimento precisa transcender o serviço de saúde e alcançar a causa da violência sexual.

O "efeito cumulativo" produzido na vida das mulheres pela VS incorpora-se e se reproduz intersubjetivamente, tornando a mulher emotiva, frágil e vulnerável, pois a constante lembrança da agressão produz uma cascata de sentimentos e medos que passam a ser potencializados com a recidiva da violência ${ }^{(28,32)}$.

"Causa uma destruição no funcionamento psicológico da vítima. Porque impacta logo a autoestima, a autoimagem, e tem o estresse pós-traumático. Porque dependendo de como essa situação é feita, e geralmente é [...] muito violenta, a pessoa fica traumatizada." (PA15)

Atuando na esfera psicológica, física, sociocomportamental e sexual, variando entre fobias, dores sem causa aparente, lesões na genital, edemas, gravidez indesejada, aborto, transtornos de comportamento e alimentares, anorgasmia, ninfomania, depressão, ansiedade, medo, contaminação com DST e o vírus da Imunodeficiência Humana (HIV), as mulheres podem desenvolver comportamentos antissociais, como a perpetuação do ciclo da violência ${ }^{(4,20,29,33)}$.

"Eu acho que gera mais ainda violência. Uma das repercussões dessa violência é gerar mais violência, principalmente intrafamiliar. [A] familia[fica] realmente desarticulada." (Asa10)

A reprodução da violência pelas mulheres foi identificada nos relatos dos profissionais de saúde do presente estudo. Sabe-se que a violência acontece nos espaços públicos e privados, mas a invisibilidade da VS ocorre no espaço doméstico, pois nesse ambiente permite a replicação crônica na vida das mulheres, assim, a percepção delas fica turva diante da naturalização da violência ${ }^{(10,14)}$.

As analisadas mulheres tornam-se parcialmente incapazes de reconhecer o ato como uma violência, e o agressor, muitas vezes, não tem conhecimento de que o ato é legalmente abusivo. $\mathrm{Na}$ esperança de que o relacionamento conjugal melhore, a mulher permanece nessa relação ${ }^{(19)}$.

Entende-se que elas são impossibilitadas justamente pela naturalização das relações de gênero, mas com a atenção adequada e com profissionais qualificados elas podem começar a se perceber violentadas e empoderaremse sobre a permanência no casamento, o medo de falar e outros elementos.

"Mulheres que sofrem violência dos seus companheiros, dos maridos, muitas vezes são forçadas, mas esse tipo de violência acaba que [...] quase não chega ou não aparece na unidade de saúde. Essa violência é mais colocada quando é na rua." (ASa9)

$\mathrm{O}$ relato dos profissionais investigados acerca da inexistência, na unidade, de mulheres em situação de VS que possuem companheiro provoca uma reflexão quanto à efetiva inexistência dos casos ou à incapacidade desses profissionais em identificá-los. A mecanização dos serviços de saúde e a dinâmica dos serviços de emergência podem ter engessado os profissionais nos protocolos e rotinas das unidades de atendimento, fazendo com que não tenham possibilidade de reflexão e identificação das mensagens não verbais dos pacientes acerca da VS crônica.

A repercussão da VS para as mulheres possui influência direta com a estrutura para o atendimento nos serviços de saúde. Identificou-se que sete dos serviços de saúde do presente estudo não estão preparados para oferecer a atenção necessária a essas mulheres e não têm estrutura física para atendê-las, como ambiente adequado para o atendimento, capacitação para atender as mulheres, medicações e materiais educativos ${ }^{(13,34)}$. Essa limitação do serviço repercute na incapacidade da mulher de ser identificada e orientada sobre os seus direitos para conseguir sair da situação de violência sexual ${ }^{(34)}$. 
"Outra coisa é aquela violência do dia a dia, que muitas vezes passa despercebida, e o profissional de saúde às vezes atende aquela paciente e não está alerta para isso e não percebe." (Ma23)

O profissional de saúde tem a responsabilidade de informar as mulheres sobre os seus direitos sexuais e reprodutivos e quais as condutas são legalmente permitidas em todas as situações que envolvem a violência sexual ${ }^{(7)}$.

Desvelou-se, a partir dos relatos dos entrevistados na presente pesquisa, uma realidade distante da esperada, pois estes acreditam compreender as repercussões da VS, mas assumem uma postura de desconhecimento sobre qual conduta realizar quando o atendimento transcende a violência física e pontuam a necessidade de estruturas adequadas para o atendimento.

\section{CONSIDERAÇÕES FINAIS}

O estudo possibilitou a análise dos sentidos atribuídos da violência sexual pela ótica dos profissionais de saúde investigados. As falas divergiram sobre a desigualdade de gênero e contexto social, mas reproduzem preconceitos não superados na cultura contemporânea, principalmente quando se vincula a violência sexual ao caso de polícia que distancia o atendimento da saúde e transfere a responsabilidade na condução dos atendimentos.

As causas da violência sexual foram apontadas como sendo a cultura machista, muito presente no Nordeste, a falta de informação das mulheres sobre os seus direitos e as questões sociais. As repercussões pontuadas foram exposição às Doenças Sexualmente Transmissíveis, problemas psicológicos e físicos, causas e reprodução do ciclo da violência sexual.

Identificou-se dificuldade dos profissionais em trabalhar com o tema, remetendo a uma falta de reflexão ou até mesmo conhecimento do que seja violência; e o não questionamento, aliado a uma falta de capacitação que os ajude a pensar, torna-se uma situação crítica para os pacientes e a reprodução da violência.

Encontrou-se que a formação profissional e a inserção nos serviços especializados em saúde da mulher ofereceram aos entrevistados, pela vivência da assistência, uma compreensão que nem sempre estava isenta de julgamentos e preconceitos.

\section{REFERÊNCIAS}

1. Organização Mundial da Saúde - OMS. Violence against women. 2013 [acesso em 2015 Nov 15]. Disponível em: http://www.who.int/mediacentre/ factsheets/fs239/en/.
2. Schraiber LB. Violence: an issue at the interface between health and society. Saúde Soc. 2014;23(3):727-32.

3. Menezes PRM, Lima IS, Correia CM, Souza SS, Erdmann AL, Gomes NP. Enfrentamento da violência contra a mulher: articulação intersetorial e atenção integral. Saúde Soc. 2014;23(3):45-52.

4. Secretaria Especial de Política para as Mulheres (BR). Fortalecimento da Secretaria Especial de Políticas para as Mulheres: avançar na transversalidade da perspectiva de gênero nas políticas públicas. Brasília: Secretaria Especial de Política para as Mulheres; 2005.

5. Contreras JM, Bott S, Guedes A, Dartnall E. Violência sexual na América Latina e no Caribe: uma análise de dados secundários. Iniciativa de Pesquisa sobre Violência Sexual. África do Sul: Conselho de Pesquisa Médica; 2010

6. Fórum Brasileiro de Segurança Pública. Anuário Brasileiro de Segurança Pública. São Paulo: Fórum Brasileiro de Segurança Pública; 2014.

7. Ministério da Saúde (BR), Secretaria de Atenção à Saúde, Departamento de Ações Programáticas Estratégicas. Prevenção e tratamento dos agravos resultantes da violência sexual contra mulheres e adolescentes: norma técnica. Brasília: Ministério da Saúde; 2012.

8. Secretaria de Políticas para as Mulheres (BR). Plano Nacional de Políticas para as Mulheres. Brasília: Secretaria de Políticas para as Mulheres; 2013.

9. Gomes R. Análise e interpretação de dados de pesquisa qualitativa. In: Minayo MCS, Deslandes SF, Gomes R. Pesquisa Social: teoria, método e criatividade. $33^{\mathrm{a}}$ ed. Petrópolis: Vozes; 2013. p. 79-108.

10. Farias RS, Cavalcanti LF. Atuação diante das situações de aborto legal na perspectiva dos profissionais de saúde do Hospital Municipal Fernando Magalhães. Ciênc Saúde Coletiva. 2012;17(7):1755-63.

11. Rosa SD, Lopes RE. Residência multiprofissional em saúde e pós-graduação lato sensu no Brasil: apontamentos históricos. Trab Educ Saúde. 2009;7(3):479-98.

12. Dias HS, Lima LD, Teixeira M. A trajetória da política nacional de reorientação da formação profissional em saúde no SUS. Ciênc Saúde Coletiva. 2013;18(6):161324.

13. Scherer MDA, Pires DEP, Jean R. A construção da interdisciplinaridade no trabalho da Equipe de Saúde da Família. Ciênc Saúde Coletiva. 2013;18(11): 3203-12. 
14. Convenção sobre a Eliminação de todas as Formas de Discriminação contra a Mulher - CEDAW. 1979 [acesso em 2015 Jul 10]. Disponível em: http://compromissoeatitude.org.br/wp-content/ uploads/2012/08/SPM2006_CEDAW_portugues.pdf

15. Secretaria de Políticas para as Mulheres (BR), Secretaria Nacional de Enfrentamento à Violência contra as Mulheres. Pacto Nacional de Enfrentamento à Violência contra as Mulheres. Brasília: Secretaria de Políticas para as Mulheres; 2011.

16. Prá JR, Epping L. Cidadania e feminismo no reconhecimento dos direitos humanos das mulheres. Rev Estud Fem. 2012;20(1):33-51.

17. Cavalcanti LF, Gomes R, Minayo MCS. Representações sociais de profissionais de saúde sobre violência sexual contra a mulher: estudo em três maternidades públicas municipais do Rio de Janeiro, Brasil. Cad Saúde Pública. 2016;22(1):31-9.

18. Bourdier P. A dominação masculina. Rio de Janeiro: Kuhner; 2002.

19. Benute GRG, Nonnenmacher D, Nomura RMY, Lucia MCS, Zugaib M. Influência da percepção dos profissionais quanto ao aborto provocado na atenção à saúde da mulher. Rev Bras Ginecol Obstet. 2012;34(2):69-73.

20. Butler J. Problemas de gênero: feminismo como subversão da identidade. Rio de Janeiro: Civilização Brasileira; 2003.

21. Najiane $\mathrm{K}$, Assis $\mathrm{SG}$, Constantino P. Impactos da violência. $2^{\mathrm{a}}$ ed. Rio de Janeiro: Fundação Oswaldo Cruz; Educação a Distância da Escola Nacional de Saúde Pública Sergio Arouca; 2009.

22. Osis MJD, Duarte GA, Faúndes A. Violência entre usuárias de unidades de saúde: prevalência, perspectiva e conduta de gestores e profissionais. Rev Saúde Pública. 2012;46(2):351-8.

23. Souza CDS, Costa MCO, Assis SG, Musse JDO, Nascimento CN Sobrinho, Amaral MTR. Sistema de Vigilância de Violências e Acidentes/ VIVA e a notificação da violência infanto-juvenil, no Sistema Único de Saúde/ SUS de Feira de Santana-Bahia, Brasil. Ciênc Saúde Coletiva. 2014;19(3):773-84.

24. Macy RJ, Giattina MC, Parish SL, Crosby C. Domestic violence and sexual assault services: historical concerns and contemporary challenges. J Interpers Violence. 2010;25(1):3-32.
25. Bruno C, Rocha A. Um pequeno guia ao pensamento, aos conceitos e à obra de Judith Butler. Cad Pagu. 2014;43:507-16.

26. Moura LBA, Lefevre F, Moura V. Narrativas de violências praticadas por parceiros íntimos contra mulheres. Ciênc Saúde Coletiva. 2012;17(4):1025-35.

27. Meneghel SN, Barbiani R, Brener C, Teixeira G, Sttefen H, Silva LB et al. Cotidiano ritualizado: grupos de mulheres no enfrentamento à violência de gênero. Ciênc Saúde Coletiva. 2005;10(1):111-8.

28. Gaitán H. La discriminación y la violencia sexual contra la mujer: problema de interés para los ginecólogos y profesiona les de la salud en atención primaria. Rev Colomb Obstet Ginecol. 2013;64(1):8-9.

29. Dalal K, Andrews J, Dawad S. Contraception use and associations with intimate partner violence among women in Bangladesh. J Biosoc Sci. 2011;44(1):83-94.

30. Kiss LB, Schraiber LB. Temas médico-sociais e a intervenção em saúde: a violência contra mulheres no discurso dos profissionais. Ciênc Saúde Coletiva. 2011;16(3):1943-52.

31. Moura LBA, Gandolfi L, Vasconcelos AMN, Pratesi R. Violências contra mulheres por parceiro íntimo em área urbana economicamente vulnerável, Brasília, DF. Rev Saúde Pública. 2009;43(6):944-53.

32. Almeida-Prado MCC, Feres-Carneiro T. Abuso sexual e traumatismo psíquico. Interações Estud Pesqui Psicol. 2005;10(20):11-34.

33. Scarpati AS, Guerra VM, Duarte CNB. Adaptação da Escala de Aceitação dos Mitos de Estupro: evidências de validade. Aval Psicol. 2014;13(1):57-65.

34. Cavalcanti LF, Flach RMD, Farias RS. Atenção às mulheres em situação de violência sexual nos serviços de saúde do Estado do Rio de Janeiro. Social Questão. 2012;14(28):99-124.

\section{Endereço para correspondência:}

Juliana da Fonseca Bezerra

Universidade Estadual de Campinas - UNICAMP

Pós Graduação em Saúde Coletiva

Rua: Teresa Bonato Signori, 51

Bairro: Barão Geraldo

CEP: 13083970 - Campinas - SP - Brasil

E-mail: ju25fb@hotmail.com 